\title{
Governança e gestão de recursos hídricos na Amazônia Oriental
}

\section{Caroline Araújo Rodrigues ${ }^{1}$, Carla Renata de Oliveira Carneiro $^{2}$ e Altem Nascimento Pontes ${ }^{3}$}

${ }^{1}$ Universidade do Estado do Pará. Curso de Graduação em Engenharia Ambiental e Sanitária. Travessa Dr. Eneas Pinheiro, 2626. Marco. Belém-PA, Brasil (CEP 66095-015). E-mail: rodriguescaroline057@gmail.com.

${ }^{2}$ Universidade do Estado do Pará. Programa de Pós-Graduação em Ciências Ambientais. Travessa Dr. Eneas Pinheiro, 2626. Marco. Belém-PA, Brasil (CEP 66095-015)

${ }^{3}$ Universidade Federal do Pará. Centro de Ciências Exatas e Naturais. Departamento de Física. Laboratório de Física Pesquisa. Rua Augusto Corrêa, 01, Sala 17. Guamá. Belém-PA, Brasil (CEP 66075-110).

Resumo. A legislação vigente que discorre sobre o uso da água tem grande importância, juntamente à maneira como é desenvolvida e aplicada pelos órgãos gestores. Sendo assim, o objetivo do presente trabalho foi analisar a conjuntura atual da gestão dos recursos hídricos nos estados da Amazônia Oriental e as condições similares entre os respectivos estados que compõem a referida área de estudo. Em termos metodológicos, a pesquisa foi bibliográfica e documental, tomando como base obras científicas e textos legislativos, além disso, obteve caráter exploratório por investigar a atual governança da gestão hídrica na Amazônia Oriental, com abordagem qualitativa. A coleta de dados aconteceu pelo levantamento de documentos legais como a política estadual de recursos hídricos de cada estado, com foco nos comitês de bacias hidrográficas, conselho estadual de recursos hídricos, órgão gestor de recursos hídricos, plano de educação ambiental e instrumentos de gestão, bem como artigos científicos com temas dos estados que compõem a Amazônia Oriental em relação à gestão desses recursos. Os resultados mostraram consistência na legislação dos cinco estados, com destaque para alguns deles. Mato Grosso e Tocantins possuem dez e seis comitês de bacias, respectivamente, bem mais que o restante dos estados. Amapá e Pará possuem a seu favor um conselho estadual de recursos hídricos que trabalha na aprovação e divulgação de relatórios referentes à situação dos recursos hídricos nesses estados. Enquanto as legislações do Pará e Tocantins foram as únicas a englobar o plano de educação ambiental dentro da política estadual de recursos hídricos. As legislações dos estados em questão apresentaram boas ferramentas de gestão e normas para governança, além de demonstrarem interesse na constante evolução e melhoria de leis e decretos acerca do uso sustentável da água.
Recebido

$21 / 03 / 2021$

Aceito

$25 / 04 / 2021$

Publicado

$30 / 04 / 2021$

Acesso aberto

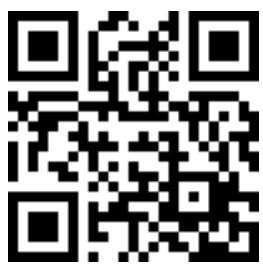

ORCID

(1) 0000-0002-8603-4417

Caroline Araújo

Rodrigues

(D) 0000-0003-4147-2605

Carla Renata de

Oliveira Carneiro

D 0000-0002-9001-4603

Altem Nascimento

Pontes

ISSN 2359-1412/RBGAS-2021-0030/2021/8/18/40/621

Rev. Bras. Gest. Amb. Sustent.

http://revista.ecogestaobrasil.net 
Palavras-chave: Legislação; Sustentabilidade; Uso da água.

Abstract. Governance and water resource management in the Eastern Amazon. The current laws that discuss the use of water are of great importance, as well as the way they are developed and applied by organs management bodies. Therefore, the objective of the present work was to analyze the current situation of water resources management in the states of the Eastern Amazon and the similar conditions between the specific states that make up a functional study area. In methodological terms, the research was bibliographic and documentary, based on scientific works and legislative texts, in addition, obtained an exploratory character by investigating the current governance of water management in the Eastern Amazon, with a qualitative approach. Data collection took place through the survey of legal documents such as the state water resources policy of each state, with a focus on river basin committees, state water resources council, water resources management body, environmental education plan and management instruments, as well as scientific articles with themes from the states that make up the Eastern Amazon in relation to the management of these resources. The results induced consistency in the legislations of the five states, with emphasis on some of them. Mato Grosso and Tocantins have ten and six basin committees, respectively, much more than the rest of the states. Amapá and Pará have a favor with a state water resources council that works on approving and disseminating reports regarding the state of water resources in the states. While the laws of Pará and Tocantins were the only ones to include the environmental education plan within the state water resources policy. The dissipating state legislations are good management tools and governance standards, in addition to showing interest in the constant evolution and improvement of laws and decrees on sustainable water use.

Keywords: Legislation; Sustainability; Use of water.

\section{Introdução}

A água funciona como limitador da vida humana e é sabido que sua escassez está no centro de grandes conflitos, visto que todas as áreas da economia de subsistência e produção de bens dependem deste recurso como insumo primordial (Borba et al., 2018). De acordo com Mesquita (2018), os recursos hídricos detêm importância para a economia do País uma vez que geram serviços para a população, motivo pelo qual torna-se imperiosa a necessidade de preservação do meio ambiente e da própria água, através de uma boa gestão e gerenciamento destes recursos.

A necessidade de valoração dos recursos hídricos está em pauta no Brasil desde o século XIX devido à importância desse bem para a economia, principalmente no que tange ao setor de energia elétrica (CETESB, 2020). Dessa maneira, o Decreto no 24.643/1934 (Brasil, 1934), instituiu o Código de Águas, com intuito de preservar e proteger os recursos hídricos, expressando a proibição de poluição e uso errôneo desses recursos, visto que até 
a data deste decreto o Brasil ainda não possuía uma legislação sobre águas que atendesse a necessidade coletiva nacional (Brasil, 1934).

A Política Nacional de Recursos Hídricos, também conhecida como Lei das Águas, foi instituída pela Lei no 9.433/1997, criando o sistema nacional de gerenciamento de recursos hídricos (Brasil, 1997). Seus objetivos são organizados em quatro itens pautados principalmente no uso consciente e no desenvolvimento sustentável, a fim de: manter a disponibilidade da água em níveis de qualidade adequados aos respectivos usos, seu uso racional destacando-se o transporte aquaviário como meio de desenvolvimento nacional utilizando os recursos hídricos, atenção aos eventos hidrólogicos de cunho natural ou decorrentes da utilização inadequada e destaque para o aproveitamento das águas pluviais, acompanhando de sua captação e preservação (Brasil, 1997).

Para auxiliar na gestão dos recursos hídricos, bacias hidrográficas foram criadas, onde consistem em áreas de concentração de redes de drenagem de rios e seus afluentes que ficam separados por diferenças no relevo como morros, serras e chapadas e são abastecidas por escoamento superficial ou infiltração da água da chuva no solo (Teodoro et al., 2007). As regiões hidrográficas situadas nos estados da Amazônia Oriental são a região hidrográfica amazônica, que abrange a maior parte do Pará, Mato Grosso e todo o Estado do Amapá, a Região Hidrográfica do Tocantins também está presente no Pará e Mato Grosso, enquanto a Região do Atlântico Nordeste está situada nas áreas do Maranhão e uma pequena parte do Pará (Bordalo, 2019).

A Política Nacional de Recursos Hídricos busca administrar a gestão integrada das águas de maneira a coordenar o seu uso, preservação e recuperação desses recursos, sendo assim, um meio para alcançar tais objetivos são os comitês de bacias hidrográficas, em que um grupo de pessoas se torna responsável em discutir sobre o interesse comum das águas (ANA, 2020). Os comitês de bacias estão presentes nos estados da Amazônia Oriental, sendo que o Estado do Pará conta com um comitê de bacias criado em 2019, Maranhão possui 2 comitês, Amapá 1, Tocantins 5, e o Estado do Mato Grosso possui 10 comitês (ANA, 2017).

A gestão de recursos hídricos é amparada por algumas leis como a instituída pela Política Nacional de Recursos Hídricos, no entanto, alguns estados possuem leis e conselhos estaduais que também auxiliam na administração das águas (ANA, 2016). Os estados possuem órgãos responsáveis pela gestão desses recursos, como o estado do Pará, que possui a Secretaria de Meio Ambiente e Sustentabilidade, no Maranhão e Amapá existem a Secretaria de Estado do Meio Ambiente, já no Tocantins a responsável é a Secretaria do Meio Ambiente e Recursos Hídricos, e no Mato Grosso a responsável é a Superintendência de Recursos Hídricos da Secretaria de Estado do Meio Ambiente (ANA, 2016).

A água como bem comum e indispensável para a sobrevivência de toda a vida na terra, se torna um elemento de interesse universal entre sociedade, estado e indústrias como insumo produtivo e de subsistência, sendo importante a administração desse bem para suprir as necessidades dos segmentos interessados (Morais et al., 2018). Sendo assim, o objetivo do presente trabalho foi analisar a conjuntura atual da gestão dos recursos hídricos nos Estados da Amazônia Oriental e as condições similares entre os respectivos estados que compõem a referida área de estudo.

\section{Material e métodos}

\section{Área de estudo}

A Amazônia Oriental faz parte da Amazônia Legal, que, por sua vez, é a área de atuação da Superintendência de Desenvolvimento da Amazônia, criada em 1950, pelo governo brasileiro no intuito de desenvolver e integrar a Região da Bacia Amazônica (IBGE, 2019). Os Estados do Pará e Amapá se encontram no bioma amazônico, Maranhão e 
Mato Grosso compartilham mais de um bioma, sendo o amazônico e também o cerrado, enquanto que o Tocantins está apenas no cerrado (IBGE, 2020). A área territorial e os habitantes de cada estado podem ser observados no Tabela 1.

Tabela 1. Área territorial e população estimada dos estados da Amazônia Oriental.

\begin{tabular}{|l|c|c|}
\hline Estados da Amazônia Oriental & Área territorial $\mathbf{( k m}^{2} \mathbf{)}$ & Habitantes \\
\hline Amapá & $142.470,762$ & 861.773 \\
\hline Maranhão & $329.642,182$ & 7.114 .598 \\
\hline Mato Grosso & $903.207,019$ & 3.526 .220 \\
\hline Pará & $1.245 .870,798$ & 8.690 .745 \\
\hline Tocantins & $277.466,763$ & 1.590 .248 \\
\hline
\end{tabular}

Fonte: IBGE (2020).

Na Figura 1 estão representados os estados da Amazônia Oriental. Nos Estado do Pará e Amapá o clima é considerado tropical, Mato Grosso e Maranhão apresentam clima equatorial e também tropical, enquanto Tocantins apresenta um clima predominantemente tropical (IBGE, 2020).

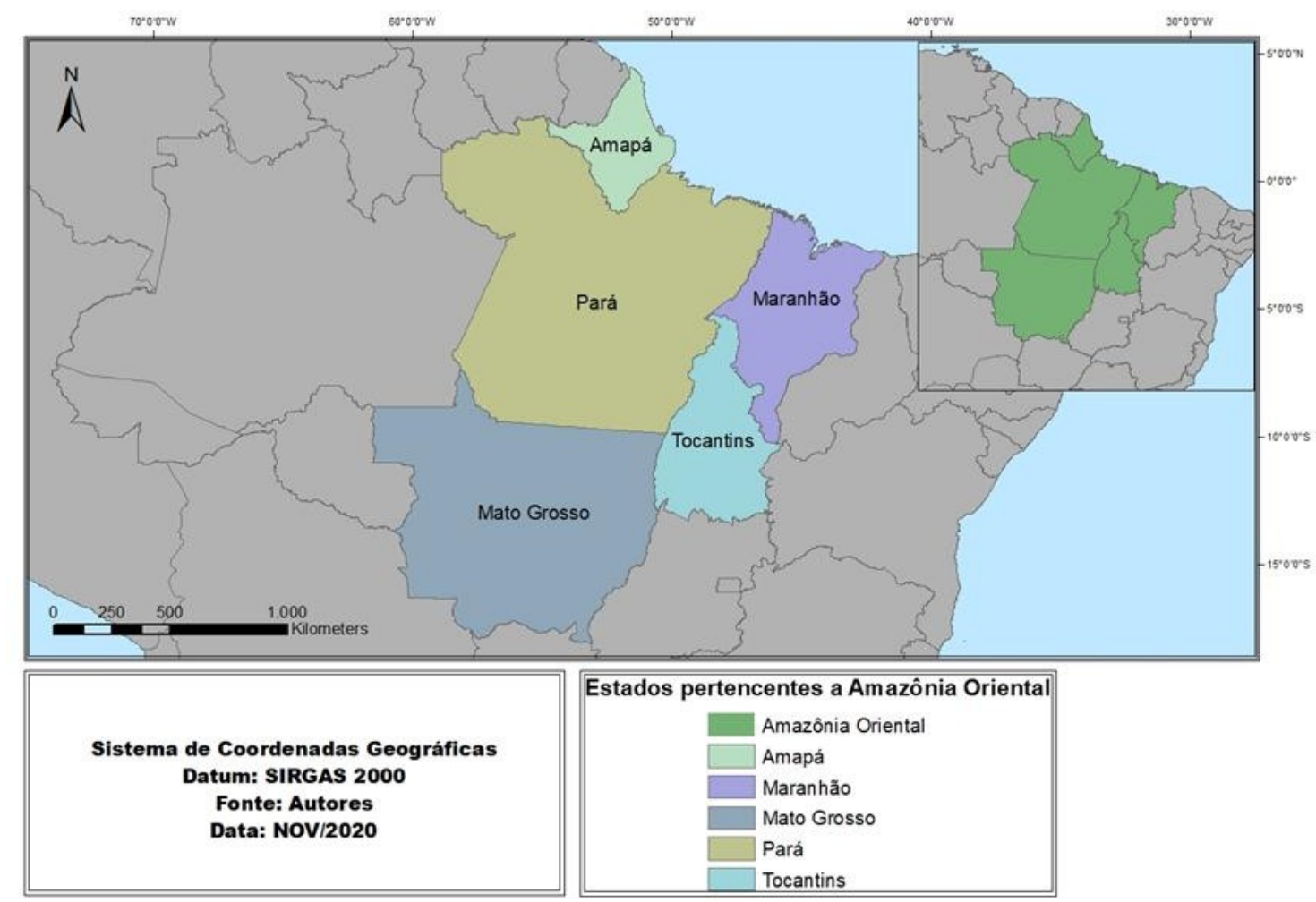

Figura 1. Estados constituintes da Amazônia Oriental.

\section{Caracterização da pesquisa}

Quanto aos procedimentos, a presente pesquisa foi bibliográfica e documental, haja vista buscar embasamento teórico e legal através de um conjunto de obras científicas já publicadas e textos legislativos que tratam da matéria pesquisada. Paralelo a isso é exploratória, uma vez que têm caráter investigativo quanto à governança e gestão atual 
dos recursos hídricos na área de estudo. Sua abordagem é qualitativa, em razão da análise dos aspectos e desdobramentos dos fatores dos fenômenos estudados.

A coleta de dados deu-se através do levantamento, estudo e compreensão dos documentos legais como a política estadual de recursos hídricos de cada estado, com foco nos comitês de bacias hidrográficas, conselho estadual de recursos hídricos, órgão gestor de recursos hídricos, plano de educação ambiental e Instrumentos de Gestão, bem como artigos científicos com temas dos estados que compõem a Amazônia Oriental em relação à gestão desses recursos, e sua análise buscou enfatizar e traçar um comparativo quanto aos procedimentos dos órgãos que atuam na referida gestão e governança de cada estado componente da Amazônia Oriental.

\section{Resultados e discussão}

Política Estadual de Recursos Hídricos e Sistema Estadual de Gerenciamento de Recursos Hídricos

Todos os componentes da Amazônia Oriental possuem uma política estadual de recursos hídricos que está prevista por uma lei intrínseca de cada estado:

- Amapá: A Política de Gerenciamento dos Recursos Hídricos do Estado do Amapá foi instituída pela Lei no 686/2002 (Amapá, 2002).

- Maranhão: Política Estadual de Recursos Hídricos, Sistema de Gerenciamento Integrado de Recursos Hídricos, Lei no 8.149/2004 (Maranhão, 2004).

- Mato Grosso: Política Estadual de Recursos Hídricos institui o Sistema Estadual de Recursos Hídricos, Lei no 11.088/2020 (Mato Grosso, 2020).

- Pará: Política Estadual de Recursos Hídricos, institui o Sistema Estadual de Gerenciamento de Recursos Hídricos, Lei no 6.381/2001 (Pará, 2001).

- Tocantins: Política Estadual de Recursos Hídricos, Lei no 1.307/2002 (Tocantins, 2002).

Na Tabela 1 podem ser visualizados os principais pontos convergentes na legislação do Pará, Amapá, Mato Grosso, Maranhão e Tocantins, com enfoque em seus fundamentos e princípios, objetivos e diretrizes gerais. Em relação a tais requisitos, é observada a preocupação com o gerenciamento ambientalmente sustentável dos recursos hídricos juntamente com desenvolvimento social e econômico, sendo de extrema relevância, posto que os recursos hídricos e seu uso sustentável estão pautados como uma das preocupações mais urgentes da sociedade atual (Grubba e Hamel, 2016).

É cristalino que os pontos convergentes entre as políticas comparadas colocam a proteção sustentável da água como elemento principal para onde os esforços de todos os atores envolvidos devem se voltar, tendo ponto comum em relação ao seu uso, a utilização prioritária para consumo humano e de animais, dando ênfase aqui ao seu valor para a sobrevivência dos seres vivos. Quando todas as políticas estaduais inserem como princípio a importância da água como um recurso de domínio público e limitado, não apenas reitera o art. 1ํㅡ, da Política Nacional (Brasil, 1997), como também cria uma máxima de proteção que vai além dos limites territoriais de cada estado, pois a necessidade de proteção da água e a garantia de sua disponibilidade a todos é imposta como algo de caráter universal e de patrimônio comum. 
Tabela 1. Pontos convergentes entre as Políticas Estaduais na Amazônia Oriental (Pará, Amapá, Mato Grosso, Maranhão e Tocantins).

\begin{tabular}{|c|c|c|}
\hline Fundamentos e princípios & Objetivos & Diretrizes Gerais de Ação \\
\hline $\begin{array}{l}\text { A água é um bem de domínio } \\
\text { público, sendo um recurso } \\
\text { natural limitado. }\end{array}$ & $\begin{array}{l}\text { Uso racional e consciente dos } \\
\text { recursos hídricos. }\end{array}$ & $\begin{array}{l}\text { Gestão dos recursos hídricos } \\
\text { levando em consideração a biota, } \\
\text { condições sociais, econômicas e } \\
\text { tipo de solo. }\end{array}$ \\
\hline $\begin{array}{l}\text { O uso prioritário da água será } \\
\text { consumo humano e animal. }\end{array}$ & 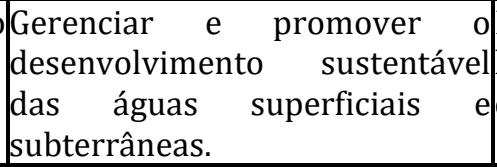 & $\begin{array}{l}\text { Integração da gestão das bacias } \\
\text { hidrográficas com a dos sistemas } \\
\text { estuarinos e zonas costeiras. }\end{array}$ \\
\hline $\begin{array}{l}\text { Garantir a disponibilidade de } \\
\text { água para as gerações futuras, } \\
\text { bem como proteger os recursos } \\
\text { hídricos. }\end{array}$ & $\begin{array}{l}\text { Prevenção e defesa de eventos } \\
\text { hidrológicos críticos de origem } \\
\text { natural. }\end{array}$ & $\begin{array}{l}\text { Adequar o plano gestor de } \\
\text { maneira a favorecer também } \\
\text { desenvolvimento econômico. }\end{array}$ \\
\hline
\end{tabular}

Fonte: Pará (2001); Amapá, (2002); Tocantins, (2002); Maranhão, (2004); Mato Grosso, (2020).

Ademais, é certo que as políticas estaduais buscam inspiração direta na política nacional de recursos hídricos, que, voltado ao conceito de governança, preleciona dois mecanismos de gestão visando a integração dos atores, quais sejam: os conselhos de recursos hídricos e os comitês de bacia hidrográfica, onde ambos os mecanismos devem voltar suas ações principalmente para o cumprimento dos princípios, objetivos e diretrizes estabelecidos (Ferreira et al., 2017).

Quanto aos objetivos das políticas analisadas, o uso racional e consciente, a promoção do desenvolvimento sustentável das águas e a prevenção dos eventos hidrológicos críticos são convergentes em todas as políticas, demonstrando que não basta apenas a afirmação da importâmcia dos recursos hídricos, mas também o movimento de ação, em favor da proteção aos princípios, através de projetos e instrumentos legais e econômicos que possam organizar a gestão da água no território, a exemplo disso, a Lei $\mathrm{n}$ o 8.091/2014 (Pará, 2014), que instituiu a Taxa de Controle, Acompanhamento e Fiscalização das Atividades de Exploração e Aproveitamento de recursos hídricos (TFRH), que possui como sujeito passivo, conforme seu art. $4^{\circ}$, a pessoa física ou jurídica que usa $o$ recurso hídrico como insumo do processo produtivo ou com a finalidade de exploração ou aproveitamento econômico (Ferreira et al., 2020).

As ações que visam a alcançar os objetivos devem ter diretrizes gerais norteadoras, para que os planos de ações não se percam em razão da complexidade da matéria e da abrangência transponível dos territórios que é peculiar dos recursos hídricos. Assim, diretrizes convergentes podem ser vistas entre as políticas analisadas, conforme 0 Quadro 1, onde em todas há a prevalência de gestão dos recursos hídricos com enfoque na biota, nas condições socioeconômicas e no tipo de solo predominante na região, ademais, deve-se adequar um plano gestor e principalmente, adequar as bacias hidrográficas com outros sistemas hídricos do território (Pará, 2001; Amapá, 2002; Tocantins, 2002; Maranhão, 2004; Mato Grosso, 2020).

Portanto, dada a importância destes pontos e vislumbrando-se ser convergentes em todos as políticas estaduais, grupos e conselhos foram criados para a execução e aplicação efetiva das referidas leis, dentre os principais que se verifica são os comitês de bacias, conselho estadual de recursos hídricos, órgão gestor de recursos hídricos e plano de educação ambiental e instrumentos como a Outorga de direito e uso dos recursos hídricos. 


\section{Comitês de bacias}

Na Figura 2 estão dispostos os comitês de bacias hidrográficas existentes na Amazônia Oriental. Tais comitês são compostos pelo poder público, por pessoas físicas ou jurídicas que necessitam de outorga para o uso da água, e pela sociedade civil, que são representantes de associações não governamentais sem fins lucrativos reconhecidos pelo conselho estadual de recursos hídricos. A importância desses comitês se justifica por serem ferramentas para o gerenciamento dos recursos hídricos de maneira descentralizada, uma vez que antes de sua existência o gerenciamento era feito pelos municípios e pelo estado (SEMA, 2018).

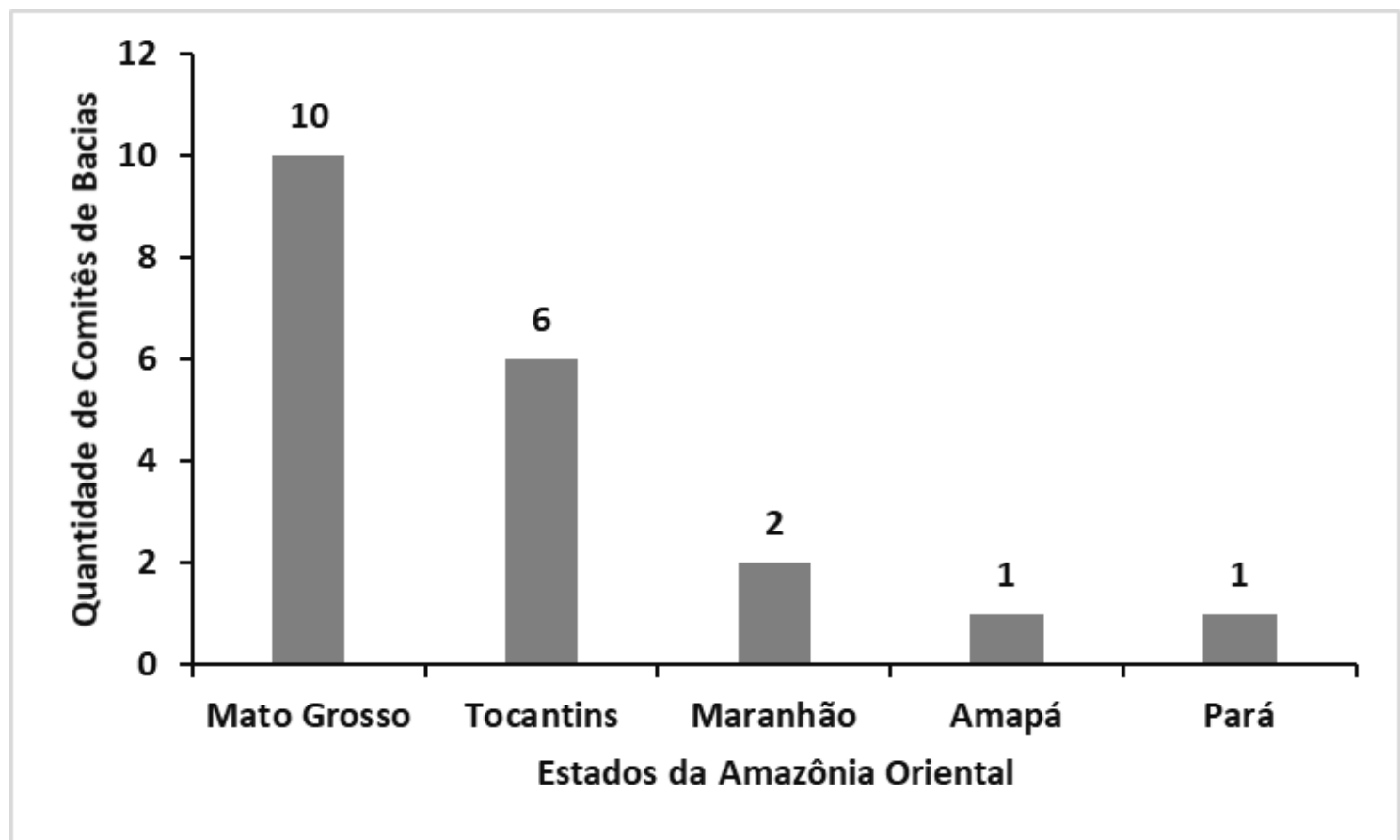

Figura 2. Quantitativo de comitês de bacias por estado da Amazônia Oriental. Fonte: ANA (2016).

Na conjectura atual, a Figura 2 demonstra que todos os estados em questão possuem ao menos um Comitê de Bacias com legislações pautadas em promover e levantar questões acerca do uso racional e sustentável dos recursos hídricos, decidindo possíveis conflitos do uso pela sociedade civil e poder público (Mesquita, 2018). Sendo assim, cada comitê atua como ferramenta essencial na gestão dos recursos hídricos, sendo importante ressaltar que não se trata de um órgão executivo, mas sim um local aberto a debates (ANA, 2017).

Ainda sobre comitês de bacias como instrumento fundamental para boa gestão dos recursos hídricos, é possível afirmar que sua criação concede participação da sociedade civil perante a gestão hídrica, principalmente em escala municipal, tendo em vista a maior aproximação e transparência entre o governo e sociedade, no entanto, ainda que o objetivo seja promover uma gestão colaborativa, a participação da população interessada ainda é mínima em relação às cadeiras ocupadas pelo poder público (Ferreira et al., 2017).

Conselho Estadual de Recursos Hídricos, órgão gestor de recursos hídricos e plano de educação ambiental 
O Conselho Estadual de Recursos Hídricos é um órgão consultivo, deliberativo e normativo que atua vinculado ao órgão gestor responsável (Pará, 2001; Amapá, 2002; Tocantins, 2002; Maranhão, 2004; Mato Grosso, 2020). Todos os componentes da Amazônia Oriental possuem um conselho estadual de recursos hídricos que foi instituído pela política estadual de recursos hídricos de cada Estado, estando atrelados aos respectivos órgãos responsáveis, conforme Tabela 2.

Tabela 2. Conselho estadual de recursos hídricos, órgão gestor de recursos hídricos e plano de educação ambiental (Pará, Amapá, Mato Grosso, Maranhão e Tocantins).

\begin{tabular}{|l|c|c|c|}
\hline Estados & $\begin{array}{c}\text { Conselho Estadual de } \\
\text { Recursos Hídricos }\end{array}$ & $\begin{array}{c}\text { Órgão Gestor de } \\
\text { Recursos Hídricos }\end{array}$ & $\begin{array}{c}\text { Plano de Educação } \\
\text { Ambiental }\end{array}$ \\
\hline Amapá & CERH/AP & SEMA/AP & Não possui \\
\hline Maranhão & CONERH/MA & SEMA/MA & Não possui \\
\hline Mato Grosso & CEHIDRO/MT & SEMA/MT & Não possui \\
\hline Pará & CERH/PA & SEMAS/PA & Possui \\
\hline Tocantins & CERH/TO & SEMARH/TO & Possui \\
\hline
\end{tabular}

Fonte: Pará (2001); Amapá, (2002); Tocantins, (2002); Maranhão, (2004); Mato Grosso, (2020).

Após análise das competências desses conselhos, foi percebido consonância principalmente quanto à aprovação de proposta, resolução de conflitos nos comitês de bacias e aprovação do plano estadual de recursos hídricos. Porém, alguns conselhos se destacaram com determinadas competências. Os Conselhos do Amapá e Pará, além das competências acima relacionadas, são responsáveis por aprovar os relatórios referentes à situação dos recursos hídricos no estado e divulgá-los publicamente (Pará, 2001; Amapá, 2002).

Ainda na Tabela 2, está representado o plano de educação ambiental. Os Estados do Amapá, Maranhão e Mato Grosso não possuem o referido plano como ferramenta dentro da política estadual de recursos hídricos. Desta maneira, se destacam os Estados do Pará e Tocantins, cuja política incorpora o plano de educação ambiental, que atuará voltado para a conservação, preservação, recuperação, expansão e valorização do uso racional e gestão dos recursos hídricos de maneira a propiciar apoio à sociedade e entidades públicas, tal prática deve ocorrer por meio da mobilização e campanhas educativas que visam à sensibilização social (Pará, 2001; Tocantins, 2002).

Em um estudo sobre educação ambiental e os impactos dentro de comunidades próximas a bacias hidrográficas acometidas por hidrelétricas, Domínguez e Pimentel (2017), expõem a importância de agregar sistemas e planos de educação ambiental como método de estímulo à conscientização social, para que assim possa ser desenvolvida uma gestão hídrica mais sustentável. Para esses autores, por meio de um programa chamado "Cultivando Água Boa", desenvolvido pela Itaipu Binacional, foi possível mitigar os impactos nas águas da Hidrelétrica de Itaipu utilizando a educação ambiental dentro da comunidade local.

\section{hídricos}

Principais instrumentos utilizados pelo poder público na gestão dos recursos

Uma ferramenta muito utilizada é a outorga de direito de uso dos recursos hídricos, que serve para garantir o controle de quantidade e qualidade de usos da água, assim como assegurar que sua finalidade atenda os direitos de acesso à água, e as prioridades de uso estabelecidas pela política estadual (Pará, 2001; Amapá, 2002; 
Tocantins, 2002; Maranhão, 2004; Mato Grosso, 2020). A importância da Outorga é percebida nos mais diversos setores ligados aos recursos hídricos, quando a Outorga é analisada de maneira articulada, juntamente ao plano de licenciamento ambiental de um empreendimento, é mais fácil integrar a gestão ambiental à de recursos hídricos (Genz et al., 2019).

Dentro da política de recursos hídricos de cada estado, existe o instrumento da cobrança pelo uso das águas, objetivando valorizar economicamente esses recursos de modo a incentivar o uso consciente dos mesmos, além de obter meios financeiros para o incentivo de programas e gerenciamento de bacias hidrográficas (Assis et al., 2018). Brito e Aguiar (2019), explicam que a crise hídrica existente em alguns países não se dá apenas pela quantidade de água disponível, mas sim pela má gestão desses bens, sendo assim, a cobrança pelo uso da água se torna um instrumento fundamental na preservação dos recursos hídricos.

Para que as informações sobre a gestão dos recursos hídricos sejam armazenadas e disseminadas com possível recuperação garantida, é utilizado um sistema de informação acerca dos recursos hídricos, cujos dados devem ser compatibilizados com o sistema nacional de informações sobre recursos hídricos, com objetivo de reunir e informar dados referentes à situação hídrica no Estado, bem como fornecer subsídios para elaboração de planos diretores de recursos hídricos (Pará, 2001; Amapá, 2002; Tocantins, 2002; Maranhão, 2004; Mato Grosso, 2020).

\section{Considerações finais}

Todos os estados da Amazônia Oriental apresentam uma política estadual de recursos hídricos consistente, por meio da qual é instituída a base legal para o gerenciamento de recursos hídricos nos Estados do Amapá, Maranhão, Mato Grosso, Pará e Tocantins. Os fundamentos, princípios, objetivos e diretrizes gerais dessas leis são semelhantes na legislação dos cinco estados, apresentando interesse comum pela água, como um recurso primordial a ser preservado por meio da colaboração de todos.

Os cinco estados possuem ao menos um Comitê de Bacias, destacam-se Mato Grosso e Tocantins com dez e seis comitês, respectivamente, agregando ganho ambiental a esses estados por meio do uso desses comitês como ferramenta de gestão no que tange o direito do uso da água e Outorga, enquanto Maranhão, com dois comitês, Pará e Amapá com um comitê cada, apesar de terem dado início à utilização dessa ferramenta de gestão, não apresentaram interesse em desenvolver mais comitês de bacias.

Os estados possuem um conselho estadual de recursos hídricos, que atua vinculado ao órgão gestor de cada Estado, apresentando grande relevância ao resolver conflitos de comitês de bacias e aprovando o plano estadual de recursos hídricos. Nesse sentido, as legislações dos estados do Amapá e Pará se sobrepõem por atuarem na aprovação e divulgação de relatórios referentes à situação dos recursos hídricos nesses estados.

Projetos e programas de educação ambiental são fundamentais para a sustentabilidade e garantia de mais consistência na gestão de recursos naturais. As legislações do Pará e Tocantins foram as únicas a englobar o plano de educação ambiental dentro da política estadual de recursos hídricos, manifestando um diferencial quando comparados às demais legislações. De modo geral, as legislações vigentes demonstram constante evolução quanto à melhoria de normas, decretos e maneiras de alcançar uma gestão mais sustentável e eficiente dos recursos hídricos.

\section{Conflito de interesses}

Os autores declaram não haver conflito de interesses. 


\section{Referências}

Amapá. Lei no 686, de 7 de junho de 2002. Dispõe sobre a Política de Gerenciamento dos Recursos Hídricos do Estado do Amapá e dá outras providências. Disponível em: $<$ http://www.al.ap.gov.br/ver_texto_lei.php?iddocumento=17698>. Acesso em: $19 \mathrm{dez}$. 2020.

ANA - Agência Nacional de Águas. Progestão. 2016. Disponível em: $<$ https://progestao.ana.gov.br>. Acesso em: 14 jan. 2021.

ANA - Agência Nacional de Águas. Tocantins formaliza participação de comitês de bacias no PROCOMITÊS. 2017. Disponível em: <https://www.gov.br/ana/pt$\mathrm{br} /$ assuntos/noticias-e-eventos/noticias/tocantins-formaliza-participacao-de-comites-debacias-no-procomites>. Acesso em: 01 nov. 2020.

ANA - Agência Nacional de Águas. Gestão de recursos hídricos. 2020. Disponível em: <https://www.gov.br/ana/>. Acesso em: 29 out. 2020.

Assis, W. D.; Ribeiro, M. M. R.; Morais, M. M. G. A. Proposição de melhoria para o sistema de cobrança pelo uso da água bruta da Bacia Hidrográfica do Rio São Francisco. Engenharia Sanitária e Ambiental, v. 23, n. 4, p. 779-790, 2018. https://doi.org/10.1590/s141341522018163489

Borba, A. L. S.; Costa, M. R.; Lima, F. B. A proteção das águas: recurso natural limitado. Anais do XX Congresso Brasileiro de Águas Subterrâneas, p. 1-4, 2018. Disponível em: <https://aguassubterraneas.abas.org/asubterraneas/article/view/29417/19019>.

Acesso em: 2 nov. 2020.

Bordalo, C. A. L. A divisão do Estado do Pará em regiões hidrográficas para o planejamento e o gerenciamento dos recursos hídricos. Anais do XVII Simpósio Brasileiro de Geografia Física Aplicada, p.1-12, 2019. Disponível em: <http://www.editora.ufc.br/ images/imagens/pdf/geografia-fisica-e-as-mudancas-globais/1098.pdf>. Acesso em: 25 out. 2020.

Brasil. Lei no 9.433, de 8 de janeiro de 1997. Institui a Política Nacional de Recursos Hídricos, cria o Sistema Nacional de Gerenciamento de Recursos Hídricos, regulamenta o inciso XIX do art. 21 da Constituição Federal, e altera o art. 1ํ da Lei no ${ }^{8.001}$, de 13 de março de 1990, que modificou a Lei no 7.990, de 28 de dezembro de 1989. Disponíel em: <http://www.planalto.gov.br/ccivil_03/leis/19433.htm>. Acesso em: 20 dez. 2020.

Brasil. Decreto no 24.643, de 10 de julho de 1934. Decreta o Código de Águas. Disponível em: <http://www.planalto.gov.br/ccivil_03/decreto/d24643compilado.htm>. Acesso em: 20 dez. 2020.

Brito, M. C. L. D. A.; Aguiar, J. C. A cobrança pelo uso da água como instrumento de gestão de recursos hídricos. Revista Direito Ambiental e Sociedade, v. 9, n. 2, p. 61-90, 2019.

CETESB - Companhia Ambiental do Estado de São Paulo. Histórico da legislação hídrica no Brasil. 2020. <https://cetesb.sp.gov.br/aguas-interiores/informacoes-basicas/tpos-deagua/historico-da-legislacao-hidrica-no-brasil/>. Acesso em: 20 nov. 2020.

Domínguez, G. D. A.; Pimentel, F. B. O Programa Cultivando Água Boa: uma avaliação desde a perspectiva da colonialidade. Hegemonia: Revista de Ciências Sociais, n. 20, p. 4-26, 2017. 
Ferreira, F. N.; Ribeiro, H. M. C.; Beltrão, N. E. S.; Pontes, A. N.; Lopes, S. R. M. Gestão de recursos hídricos na Amazônia: um panorama da participação da sociedade civil nos espaços deliberativos. HOLOS, v. 8, p. 336-351, 2017. https://doi.org/10.15628/ holos.2017.6505

Ferreira, F. N.; Ribeiro, H. M. C.; Beltrão, N. E. S.; Merlin, L. V. C. T. Instrumentos econômicos e a exploração dos recursos hídricos paraenses: taxa, compensação e cobrança pelo uso.

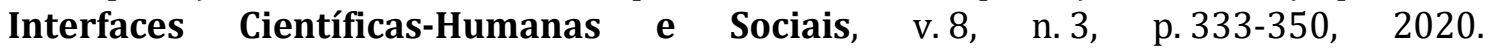
https://doi.org/10.17564/2316-3801.2020v8n3p333-350

Genz, F.; Barbosa, V. C.; Rocha, J. C. S. Integração dos procedimentos de outorga e licenciamento ambiental: estudo de caso do Estado de Sergipe. Bahia Análise \& Dados, v. 29, n. 2, p. 99-124, 2019.

Grubba, L. S.; Hamel, E. H. Desafios do desenvolvimento sustentável e os recursos naturais hídricos. Revista Brasileira de Direito, v. 12, n. 1, p. 100-111, 2016. https://doi.org/10.18256/2238-0604/revistadedireito.v12n1p100-111

IBGE - Instituto Brasileiro de Geografia e Estatistica. Amazônia Legal. 2019. Disponível em: $<$ https://www.ibge.gov.br/geociencias/cartas-e-mapas/mapas-regionais/15819-

amazonia-legal.html?=\&t=o-que-e >. Acesso em: 12 jan. 2021.

IBGE - Instituto Brasileiro de Geografia e Estatistica. IBGE Educa. 2020. Disponível em: <https://educa.ibge.gov.br/jovens/conheca-o-brasil/territorio/20644-clima.html>.

Acesso em: 20 nov. 2020.

Maranhão. Lei no 8.149, de 15 de junho de 2004. Dispõem sobre e Política Estadual de Recursos Hídricos, o Sistema de Gerenciamento Integrado de Recursos Hídricos e dá outra providencias. Disponível em: <http://arquivos.al.ma.leg.br:8080/ged/legislacao/ LEI_8149>. Acesso em: 20 dez. 2020.

Mato Grosso. Lei no 11.088, de 09 de março de 2020. Dispõe sobre a Política Estadual de Recursos Hídricos, institui o Sistema Estadual de Recursos Hídricos e dá outras providências. Disponível em: <https://www.al.mt.gov.br/storage/webdisco/leis/lei11088-2020.pdf>. Acesso em: 20 dez. 2020.

Mesquita, L. F. G. Os comitês de bacias hidrográficas e o gerenciamento integrado na política nacional de recursos hídricos. Revista Desenvolvimento e Meio Ambiente, v. 45, p. 56-80, 2018. https://doi.org/10.5380/dma.v45i0.47280

Morais, J. L. M.; Fadul, E.; Cerqueira, L. S. Limites e desafios na gestão de recursos hídricos por comitês de bacias hidrográficas: um estudo nos estados do Nordeste do Brasil. Revista Eletrônica de Administração, v. 24, n. 1, p. 238-264, 2018. https://doi.org/10.1590/ 1413-2311.187.67528

Pará. Lei no 6.381 de 25 de julho de 2001. Dispõe sobre a Política Estadual de Recursos Hídricos, institui o Sistema Estadual de Gerenciamento de Recursos Hídricos e dá outras providências. Disponível em: <https://www.abas.org/arquivos/LEI-№ 6381-01 PA.pdf>. Acesso em: 20 dez. 2020.

Pará. Lei no 8.091, de 29 de dezembro de 2014. Institui a Taxa de Controle, Acompanhamento e Fiscalização das Atividades de Exploração e Aproveitamento de Recursos Hídricos - TFRH, e o Cadastro Estadual de Controle, Acompanhamento e Fiscalização das Atividades de Exploração e Aproveitamento de Recursos Hídricos - CERH. Disponível em: <https://www.legisweb.com.br/legislacao/?id=279520>. Acesso em: 10 fev. 2021. 
SEMA - Secretaria de Estado do Meio Ambiente e Recursos Naturais. Comitês de bacias hidrográficas: gerindo os recursos hídricos. 2018. Disponível em: $<$ https://www.sema.ma.gov.br/comites-de-bacia-hidrografica-gerindo-os-recursoshidricos-2>. Acesso em: 05 dez. 2020.

Teodoro, V. L. I.; Teixeira, D.; Costa, D. J. L.; Fuller, B. B. O conceito de bacia hidrográfica e a importância da caracterização morfométrica para o entendimento da dinâmica ambiental local. Revista Brasileira Multidisciplinar, v.11, n. 1, p.137-156, 2007. https://doi.org/10.25061/2527-2675/ReBraM/2007.v11i1.236

Tocantins. Lei no 1.307, de 22 de março de 2002. Dispõe sobre a Política Estadual de Recursos Hídricos, e adota outras providências. Disponível em: <https://central3.to.gov.br/arquivo/499515/>. Acesso em: 20 dez. 2020. 